02

\title{
Механизм формирования структуры во время высокотемпературного отжига деформированных под давлением массивных образцов $\mathrm{MgB}_{2}$
}

\author{
() Е.И. Кузнецова, М.В. Дегтярев, Ю.В. Блинова, С.В. Сударева , Ю.Н. Акшенцев, В.П. Пилюгин \\ Институт физики металлов УрО РАН, \\ Екатеринбург, Россия \\ ฯ E-mail: sudareva@imp.uran.ru
}

(Поступила в Редакцию 14 марта 2017 г.)

\begin{abstract}
Методами рентгенографии, сканирующей электронной микроскопии и микроанализа исследованы сверхпроводники $\mathrm{MgB}_{2}$, подвергнутые деформации под давлением в наковальнях Бриджмена и последующим отжигам при 800 и $950^{\circ} \mathrm{C}$. Показано, что при этих температурах кристаллы фазы $\mathrm{MgB}_{2}$ вместе с остаточным бором растворяются в остаточном жидком магнии с образованием как плотных, так и рыхлых областей фазы $\mathrm{MgB}_{2}$. Последние плохо влияют на критический ток. Вместе с тем после этих обработок образцы становятся более однородными по фазовому и химическому составу.
\end{abstract}

Работа выполнена по теме „Кристалл“ (№ г.р. 01201463333) при поддержке проектом УрО РАН № 15-17-2-16.

DOI: 10.21883/FTT.2017.09.44835.076

\section{1. Введение}

Ранее в нашей работе [1] было показано, что в результате отжига при $1000^{\circ} \mathrm{C}, 2 \mathrm{~h}$ в атмосфере аргона при давлении $1 \mathrm{MPa}$ прессованных таблеток из чешуек магния (размером $\sim 50-200 \mu \mathrm{m})$ и порошка бора $(\sim 1-10 \mu \mathrm{m})$ состава $\mathrm{Mg}: \mathrm{B}=1: 2$ образуются фактически две фракции фазы $\mathrm{MgB}_{2}$, которые резко отличаются по микроструктуре. Одна образует очень плотные области, состоящие из плотно расположенных кристалликов фазы $\mathrm{MgB}_{2}$ с составом, близким к стехиометрическому. Области второго типа рыхлые - кристаллики $\mathrm{MgB}_{2}$ плохо связаны между собой, микротвердость не определяется. В этих областях имеется заметное отклонение от стехиометрии по $\mathrm{Mg}$ и В и много кислорода. Размеры областей обоих типов $100-500 \mu \mathrm{m}$; чередуясь, они заполняют все пространство образца. Критическая плотность тока определяется сеткой из плотных областей фазы $\mathrm{MgB}_{2}$, рыхлые области не благоприятствуют критическому току.

На основе данных о структуре синтезированных образцов $\mathrm{MgB}_{2}$ был предложен жидкостный механизм образования фазы $\mathrm{MgB}_{2}$ при высоких температурах (при температурах выше температуры плавления магния $649^{\circ} \mathrm{C}$ ) [1]. Бор растворяется в жидком магнии, после достижения состава $\mathrm{MgB}_{2}$ происходит кристаллизация из расплава. Плотные области - это результат первичной кристаллизации. Все избыточные атомы $(\mathrm{Mg}, \mathrm{B}$, О и другие примеси) оттесняются на границы плотных областей. Более „грязные“ рыхлые области - результат вторичной кристаллизации. В нашей работе [2] образование в синтезированных образцах $\mathrm{MgB}_{2}$ структуры из двух фракций анализируется на основе теоретических представлений о кристаллизации из расплава. Наблюде- ние слоистых структур в плотных и рыхлых областях рассматривается в качестве доказательства образования фазы $\mathrm{MgB}_{2}$ из расплава $\mathrm{Mg}: \mathrm{B}=1: 2$.

В работе [3] методом сканирующей электронной микроскопии и микроанализа показано, что в диффузионной паре $\mathrm{Mg}-\mathrm{B}$ при низких температурах (ниже температуры плавления магния) происходит твердофазное взаимодействие между $\mathrm{Mg}$ и В с образованием слоя $\mathrm{MgB}_{2}$, причем $\mathrm{Mg}$ проникает в бор. Последнее связано с тем, что коэффициент диффузии твердого $\mathrm{Mg}$ выше, чем у бора. Когда температура нагрева образца становится выше температуры плавления $\mathrm{Mg}$, коэффициент диффузии расплавленного $\mathrm{Mg}$ резко возрастает, $\mathrm{Mg}$ легко диффундирует через слой $\mathrm{MgB}_{2}$ и вступает в реакцию с В. Образование фазы $\mathrm{MgB}_{2}$ в одножильной проволоке, состоящей из $\mathrm{Mg}$-стержня, вставленного в стальной контейнер с порошком бора, при температурах выше температуры плавления $\mathrm{Mg}$ описано в работе [4]. В процессе термической обработки этой проволоки $\left(670^{\circ} \mathrm{C}, 3 \mathrm{~h} ; 700^{\circ} \mathrm{C}, 1 \mathrm{~h} ; 800^{\circ} \mathrm{C}, 1 \mathrm{~h}\right)$ жидкий $\mathrm{Mg}$ просачивается в твердый бор, и именно в цилиндре из твердого бора формируется фаза $\mathrm{MgB}_{2}$. Примечательно, что в этом случае повсеместно возникает только плотная фракция фазы $\mathrm{MgB}_{2}$. В работе [5] сообщается о получении высокоплотной, однородной, мелкозернистой, с хорошей связью между зернами фазы $\mathrm{MgB}_{2}$ методом инфильтрации, который заключается в проникновении при температуре $750^{\circ} \mathrm{C}$ жидкого $\mathrm{Mg}$ в прессованную таблетку бора. Отметим также и нашу работу [2], где говорится, что при заполнении жидким $\mathrm{Mg}$ свободного пространства между частичками бора обеспечивается наиболее интенсивное растворение бора в $\mathrm{Mg}$ из-за наличия большого количества поверхностей соприкосновения этих элементов. Поэтому можно заключить, что 
именно в этих областях в первую очередь и с большей скоростью будет происходить первичная кристаллизация из расплава $\mathrm{Mg}: \mathrm{B}=1: 2$ с образованием плотной фракции. Растворение бора в больших „резервуарах“ $\mathrm{Mg}$ процесс очень длительный.

В настоящей работе приводятся дополнительные данные, подтверждающие предложенный нами жидкостный механизм образования фазы $\mathrm{MgB}_{2}$ во время синтеза. А именно, проявление этого механизма в синтезированных, а затем деформированных под давлением и отожженных при высокой температуре образцах $\mathrm{MgB}_{2}$.

\section{2. Материал и методика эксперимента}

Образцы № 1-4 синтезированы из чешуек магния размером 50-200 $\mu \mathrm{m}$ чистотой 99.98\% и порошка металлического бора $(1-10 \mu \mathrm{m})$, полученного плавкой аморфного бора чистотой 96.93\%. Спрессованные таблетки $\mathrm{Mg}: \mathrm{B}=1: 2$ подвергали последовательному отжигу при $400^{\circ} \mathrm{C}, 15 \mathrm{~min}$ в вакууме и $900^{\circ} \mathrm{C}, 1 \mathrm{~h}$ в атмосфере аргона с водородом при давлении $0.165 \mathrm{MPa}$, за исключением образца № 2, который подвергали последовательному отжигу $400^{\circ} \mathrm{C}, 15 \mathrm{~min}$ (в вакууме) $+600^{\circ} \mathrm{C}, 2 \mathrm{~h}$ (в аргоне при давлении $0.15 \mathrm{MPa})+900^{\circ} \mathrm{C}, 1 \mathrm{~h}$ (в аргоне при давлении $0.15 \mathrm{MPa}$ ). Далее образцы были обработаны следующим образом:

Образ ец № 1. Холодная деформация в наковальнях Бриджмена под давлением $P=1.3 \mathrm{GPa}$ с углом поворота наковальни $\alpha=45^{\circ}+$ восстановительный отжиг при $950^{\circ} \mathrm{C}, 30 \mathrm{~min}$ в атмосфере аргона при давлении $1 \mathrm{MPa}$.

Образец № 2. Деформация в наковальнях Бриджмена, $P=1.3 \mathrm{GPa}, \alpha=20^{\circ}+$ отжиг при $950^{\circ} \mathrm{C}, 30 \mathrm{~min}$ в атмосфере аргона при давлении $1 \mathrm{MPa}$.

Образец № 3. Деформация в наковальнях Бриджмена, $P=1.4 \mathrm{GPa}, \alpha=20^{\circ}+$ отжиг при $800^{\circ} \mathrm{C}, 1 \mathrm{~h}$ в атмосфере аргона при давлении $0.15 \mathrm{MPa}+$ деформация в наковальнях Бриджмена сжатием без поворота, $P=0.45 \mathrm{GPa}, \alpha=0+$ отжиг при $800^{\circ} \mathrm{C}, 1 \mathrm{~h}$ в атмосфере аргона при давлении $0.15 \mathrm{MPa}$.

Образец № 4. Деформация в наковальнях Бриджмена, $P=0.9 \mathrm{GPa}, \alpha=0+$ отжиг при $800^{\circ} \mathrm{C}, 1 \mathrm{~h}$ в атмосфере аргона при давлении $0.15 \mathrm{MPa}+$ деформация в наковальнях Бриджмена, $P=0.45 \mathrm{GPa}, \alpha=0+$ отжиг при $800^{\circ} \mathrm{C}, 1 \mathrm{~h}$ в атмосфере аргона при давлении $0.15 \mathrm{MPa}$.

Структура образцов исследовалась рентгенографически на дифрактометре ДРОН-3М в излучении $\mathrm{Cr} K_{\alpha}$ и методом сканирующей электронной микроскопии (СЭМ) на приборе Quanta-200 с приставкой EDAX для микроанализа. Намагниченность измерялась вибрационным магнитометром VSM-7407, критическая плотность тока определялась из кривой намагниченности по формуле Бина. Исследования выполнены на оборудовании Центра коллективного пользования „Испытательный центр нанотехнологий и перспективных материалов“ ИФМ УрО РАН.

\section{3. Результаты и обсуждение}

Образец № 1. Синтез + холодная деформация в наковальнях Бриджмена под давлением $P=1.3 \mathrm{GPa}$, $\alpha=45^{\circ}+$ отжиг при $950^{\circ} \mathrm{C}, 30 \mathrm{~min}$. Согласно рентгенографическим данным, после синтеза этот образец состоит из основной фазы $\mathrm{MgB}_{2}$, остаточного $\mathrm{Mg}$ и фазы $\mathrm{Mg}_{2} \mathrm{~B}_{25}$ (рис. 1,a). В сканирующем электронном микроскопе наблюдаются плотные (темные) и рыхлые (светлые) области фазы $\mathrm{MgB}_{2}$ (рис. 2, $\left.a, b\right)$. После деформации фазовый состав образца практически не изменяется. Поверхность образца становится гладкой, рыхлые области исчезают, плотность образца повышается, микротвердость достигает 17-26 GPa (рис. 2,c). Увеличение микротвердости свидетельствует об усилении связи между кристалликами (зернами) фазы $\mathrm{MgB}_{2}$. Но после указанного отжига возникает структура, близкая к структуре исходного синтезированного образца (рис. 2,d). Вновь появляются рыхлые области (показаны стрелками), микротвердость в этих областях не определяется - индентор не фиксируется. Они сосуществуют с плотными областями с микротвердостью 17-31 GPa. Такая структура из двух фракций является результатом действия жидкостного механизма при температурах, превышающих температуру плавления $\mathrm{Mg}$ $\left(649^{\circ} \mathrm{C}\right)$. А именно остаточный $\mathrm{Mg}$ расплавляется, в нем растворяются кристаллы фазы $\mathrm{MgB}_{2}$ и остаточный бор с последующей кристаллизацией из расплава и образованием сначала плотных областей $\mathrm{MgB}_{2}$, а затем „загрязненных“ рыхлых участков. Действительно, по рентгенографическим данным образец после отжига при $950^{\circ} \mathrm{C}, 30 \mathrm{~min}$ представлен в основном фазой $\mathrm{MgB}_{2}$, нет чистого $\mathrm{Mg}$, есть немного фаз $\mathrm{MgO}$ и $\mathrm{Mg}_{2} \mathrm{~B}_{25}$ (рис. $1, b)$. Примечательно, что после такой обработки

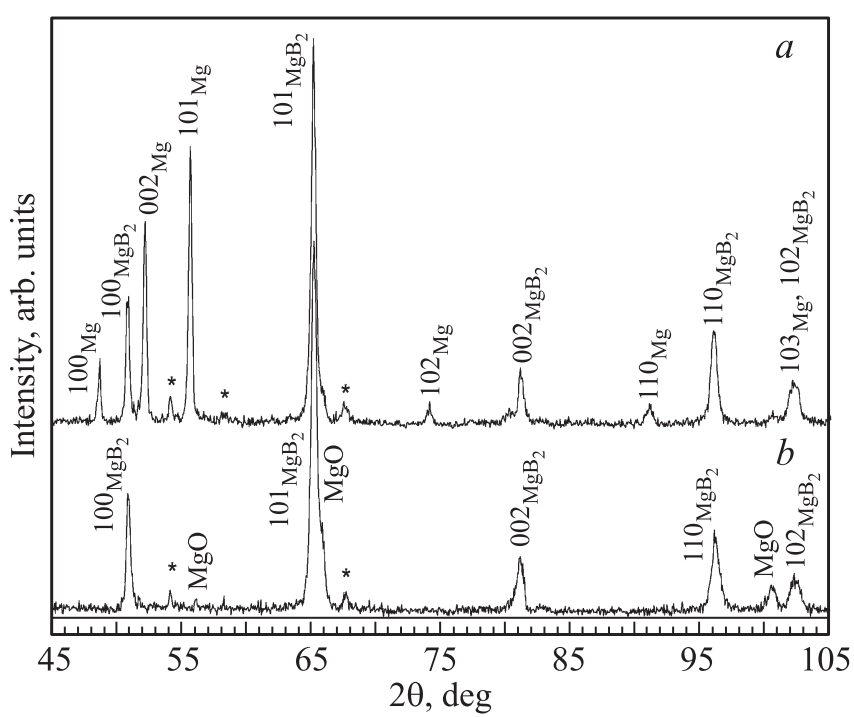

Рис. 1. Участки дифрактограмм образца № $1: a-$ исходное состояние (после синтеза); $b-$ деформация $P=1.3 \mathrm{GPa}$, $\alpha=45^{\circ}+$ отжиг $950^{\circ} \mathrm{C}, 30 \mathrm{~min}$. Символом * указаны пики фазы $\mathrm{Mg}_{2} \mathrm{~B}_{25}$. Излучение $\mathrm{Cr} K_{\alpha}$. 
$a$
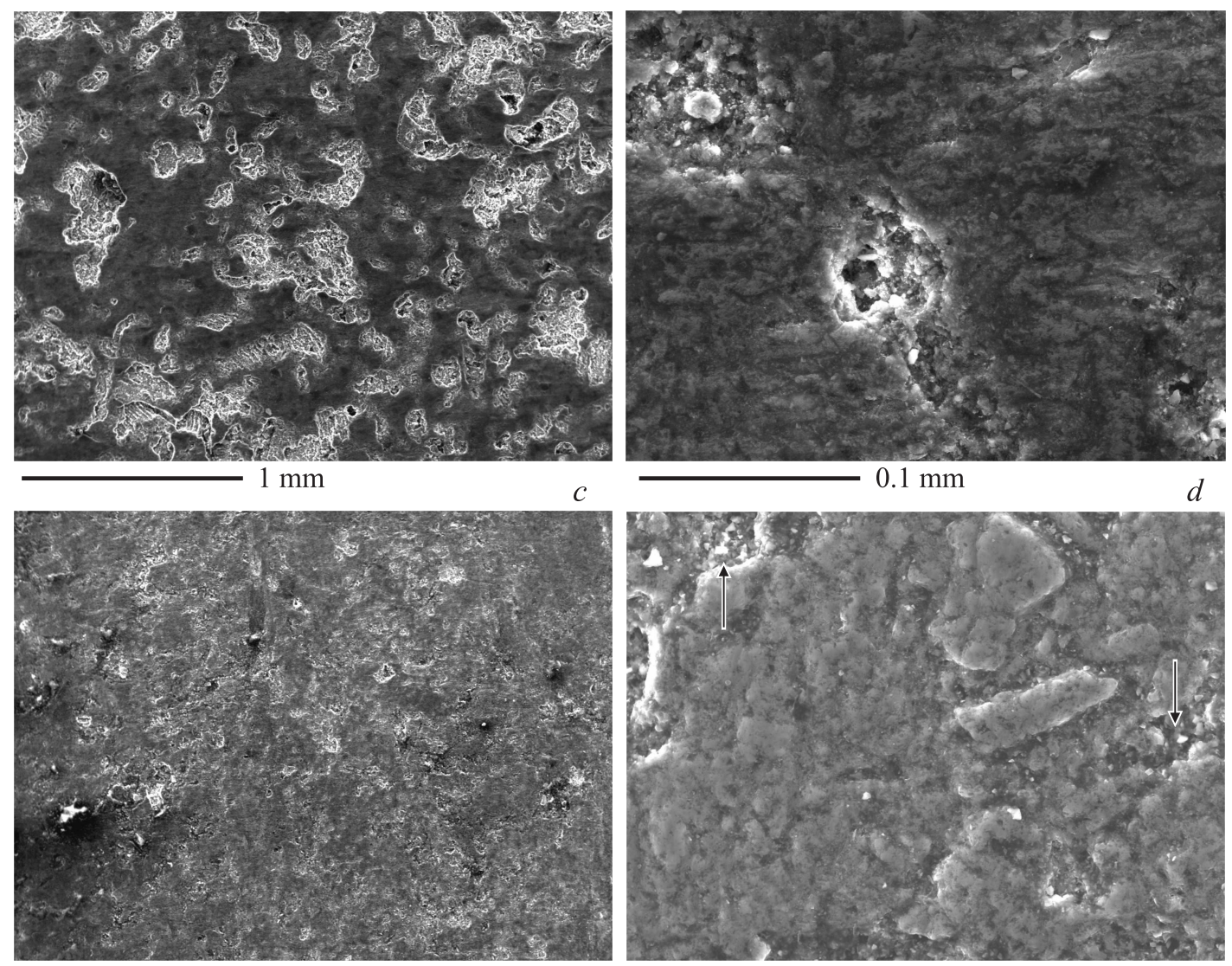

$0.1 \mathrm{~mm}$

Рис. 2. Сканирующая электронная микроскопия образца № $1: a-$ исходное состояние (после синтеза); $b-$ то же, что и $a$,

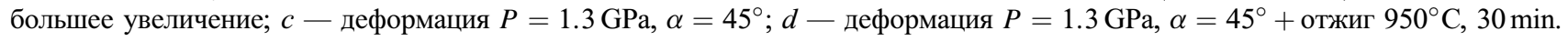

(деформация + отжиг) разница в химическом составе плотных и рыхлых областей также заметно сократилась: $\mathrm{Mg}: \mathrm{B}: \mathrm{O}=30: 62: 8$ и 29:63:9 соответственно. Критическая плотность тока этого образца $5.8 \cdot 10^{4} \mathrm{~A} / \mathrm{cm}^{2}(30 \mathrm{~K})$.

Предлагаемый нами жидкостный механизм находится в согласии с данными работы [6]. В этой работе методом дифференциального термического анализа (ДТА) показано, что в интервале температур $300-800^{\circ} \mathrm{C}$ существуют две стадии образования фазы $\mathrm{MgB}_{2}$. На первой стадии при температурах ниже температуры плавления магния идет твердофазная реакция между магнием и бором с образованием фазы $\mathrm{MgB}_{2}$. В результате на кривой теплового потока появляется сильный пик. При дальнейшем повышении температуры этот пик постепенно исчезает - возникшая фаза $\mathrm{MgB}_{2}$ растворяется в жидком магнии. В пользу такой реакции свидетельствует наличие ярко выраженного экзотермического пика на кривых ДТА $[3,6]$. После достижения насыщения $(\mathrm{Mg}: \mathrm{B}=1: 2)$ фаза $\mathrm{MgB}_{2}$ образуется вновь (сильный второй пик). На возможность „реорганизации частиц“ $\mathrm{MgB}_{2}$ во время нагрева до высоких температур указано также в обзоре [7].

О бр аз е № 2. Синтез + деформация, $P=1.3 \mathrm{GPa}$, $\alpha=20^{\circ}+$ отжиг при $950^{\circ} \mathrm{C}, 30 \mathrm{~min}$. Этот образец был подвергнут меньшей деформации, чем образец № 1 , но такому же отжигу. Рентгенограмма образца № 2 в исходном состоянии представлена на рис. 3. Как в исходном

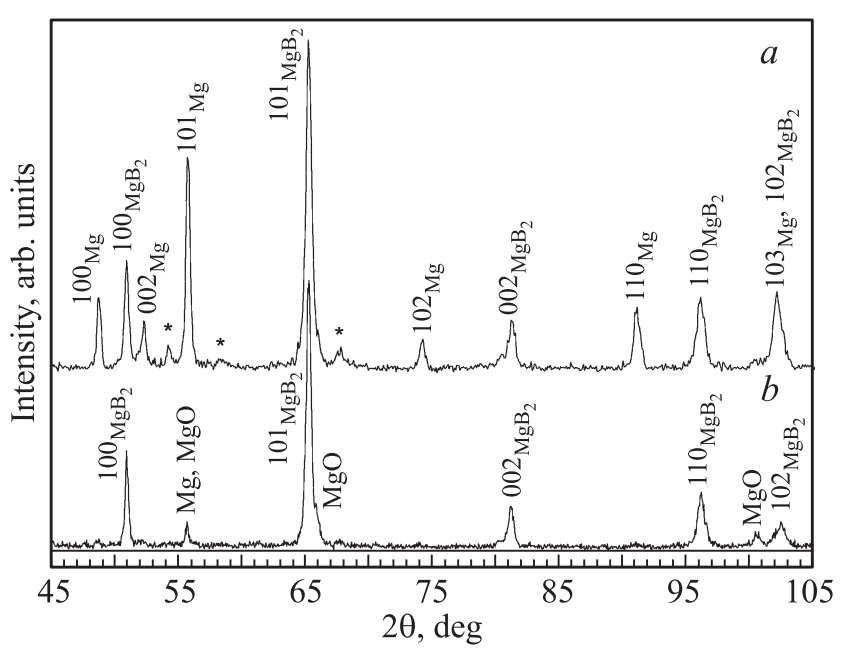

Рис. 3. Участки дифрактограмм образца № 2: $a-$ исходное состояние (после синтеза); $b-$ деформация $P=1.3 \mathrm{GPa}$, $\alpha=20^{\circ}+$ отжиг $950^{\circ} \mathrm{C}, 30 \mathrm{~min}$. Символом * указаны пики фазы $\mathrm{Mg}_{2} \mathrm{~B}_{25}$. Излучение $\mathrm{Cr} K_{\alpha}$. 

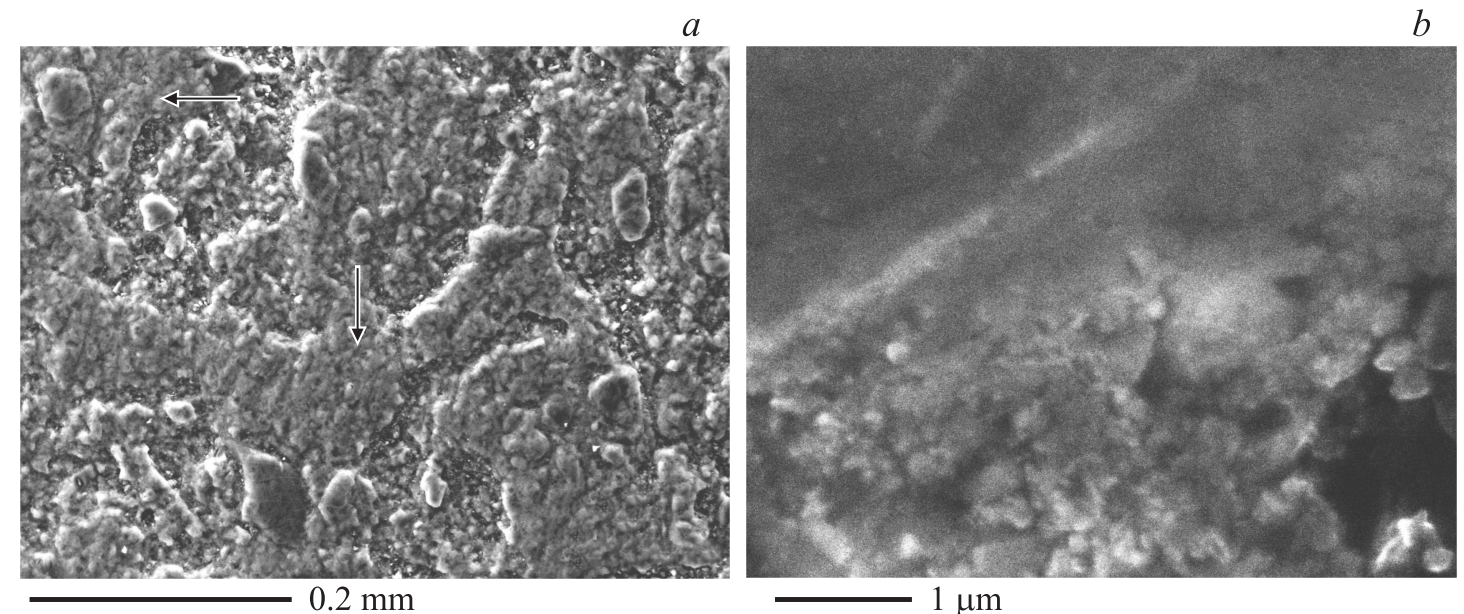

Pис. 4. Сканирующая электронная микроскопия образца № 2: $a$ - деформация $P=1.3 \mathrm{GPa}, \alpha=20^{\circ}+$ отжиг $950^{\circ} \mathrm{C}, 30 \mathrm{~min} ; b-$ то же, большее увеличение.

состоянии (после синтеза), так и после деформации фазовый состав образца практически одинаковый: это фазы $\mathrm{MgB}_{2}, \mathrm{Mg}$, немного $\mathrm{Mg}_{2} \mathrm{~B}_{25}$. Структура образца (СЭМ) в исходном состоянии и после деформации аналогична структуре образца № 1 (см. рис. 2, $a, b)$. В исходном состоянии также наблюдаются темные плотные и светлые рыхлые области. После деформации рыхлые области практически исчезают, плотность образца возрастает, поверхность становится гладкой, плотной и однородной.

Затем этот образец был подвергнут отжигу при $950^{\circ} \mathrm{C}$, $30 \mathrm{~min}$. Соответствующая рентгенограмма приведена на рис. $3, b$. Так как в исходном состоянии и после деформации, по данным рентгенографии, имеется некоторое количество остаточного магния, то происходит типичная для жидкостного механизма реакция образования фазы $\mathrm{MgB}_{2}$. Как уже отмечалось, кристаллы фазы $\mathrm{MgB}_{2}$ вместе с остаточным бором растворяются в остаточном жидком магнии, а затем образуются вновь при кристаллизации из расплава $\mathrm{Mg}: \mathrm{B}=1: 2$. Из дифрактограммы рис. $3, b$ видно, что $\mathrm{Mg}$ практически исчез. При этом возникла структура, характерная для исходного состояния (рис. 4,a). Наблюдаются крупные конгломераты, представляющие собой плотные области, в которых зерна хорошо прилегают друг к другу (результат первичной кристаллизации, показано стрелками) и рыхлые области (результат вторичной кристаллизации). На рис. $4, b$ в верхней части виден монолит, отдельные зерна в котором не выявляются, в нижней части рисунка рыхлая область. Критическая плотность тока отожженного образца достигла $5.5 \cdot 10^{4} \mathrm{~A} / \mathrm{cm}^{2}(30 \mathrm{~K})$, благодаря усилению связи между зернами фазы $\mathrm{MgB}_{2}$ в плотных областях.

Таким образом, несмотря на более низкую степень деформации жидкостный механизм проявился в данном образце во всей полноте.

Образец № 3. Синтез + деформация, $P=1.4 \mathrm{GPa}$, $\alpha=20^{\circ}+$ отжиг $800^{\circ} \mathrm{C}, 1 \mathrm{~h}+$ деформация, $P=0.45 \mathrm{GPa}$, $\alpha=0+$ отжиг $800^{\circ} \mathrm{C}, 1 \mathrm{~h}$. Первоначально перед нами стояла задача - уплотнить синтезированный образец $\mathrm{MgB}_{2}$, ликвидировать в нем нежелательные рыхлые области. Для этого была использована двухстадийная обработка, состоящая из небольших деформаций с последующими высокотемпературными отжигами при $800^{\circ} \mathrm{C}$. Полагали, что таким образом образец будет готов к восприятию большой деформации под высоким давлением - 5-6 GPa. Однако, как будет показано ниже, структура образца вернулась к исходному (после синтеза) состоянию, как и в случае однократных деформации и отжига $950^{\circ} \mathrm{C}, 30 \mathrm{~min}$.

Данные рентгеноструктурного анализа образца № 3 в исходном состоянии и после двух этапов деформации с отжигом представлены на рис. 5. Отметим, что в

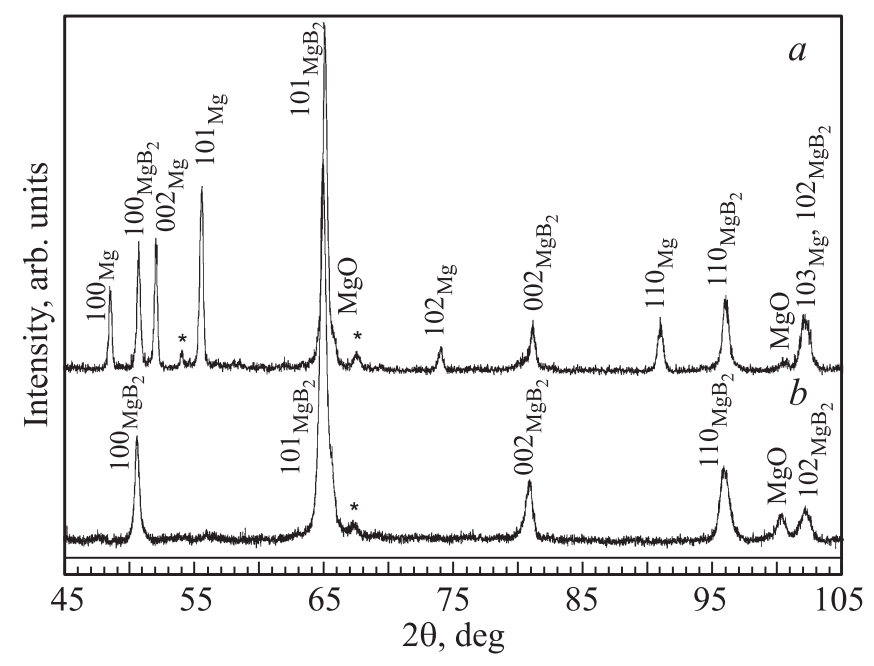

Рис. 5. Участки дифрактограмм образца № 3: $a$ исходное состояние (после синтеза); $b$ - деформация $P=1.4 \mathrm{GPa}, \alpha=20^{\circ}+$ отжиг $800^{\circ} \mathrm{C}, 1 \mathrm{~h}+$ деформация $P=0.45 \mathrm{GPa}, \alpha=0^{\circ}+$ отжиг $800^{\circ} \mathrm{C}, 1 \mathrm{~h}$. Излучение $\mathrm{Cr} K_{\alpha}$. 

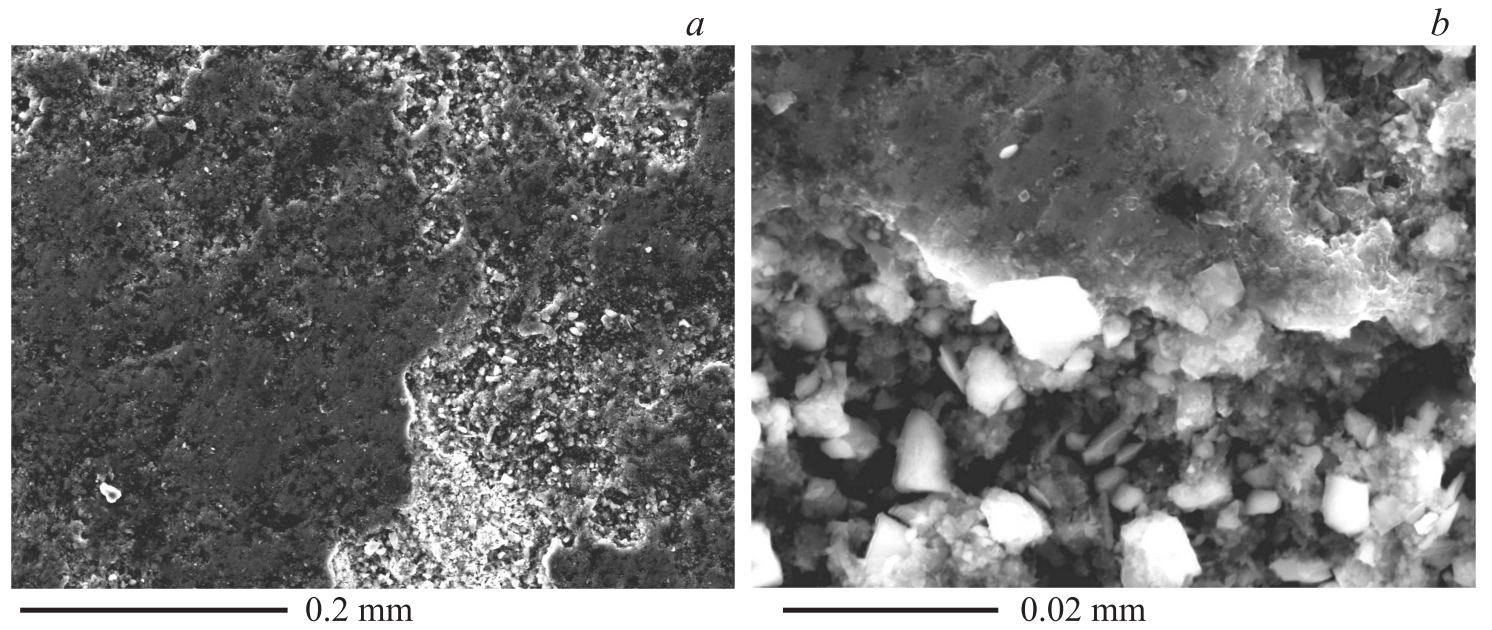

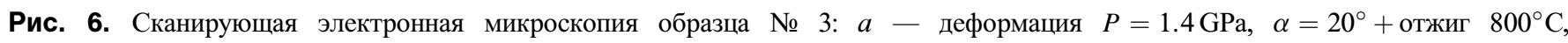
$1 \mathrm{~h}+$ деформация $P=0.45 \mathrm{GPa}, \alpha=0^{\circ}+$ отжиг $800^{\circ} \mathrm{C}, 1 \mathrm{~h} ; b-$ то же, большее увеличение.

исходном состоянии в образце присутствует достаточно большое количество остаточного магния (рис. 5, $a$ ). После четырехстадийной обработки магний исчезает (рис. $5, b)$. Это результат действия жидкостного механизма формирования фазы $\mathrm{MgB}_{2}$, как и в двух ранее описанных образцах. Структура образца после двухстадийной обработки, наблюдаемая методом СЭМ, показана на рис. 6. Характерным является присутствие в образце двух типов областей, описанных выше, плотной (результат первичной кристаллизации) и рыхлой (результат вторичной кристаллизации). В верхней части рис. $6, b$ виден монолит фазы $\mathrm{MgB}_{2}$, внизу рисунка — характерная рыхлая область с плохо связанными кристалликами.

Образ ец № 4. Синтез + деформация, $P=0.9 \mathrm{GPa}$, $\alpha=0+$ отжиг $800^{\circ} \mathrm{C}, 1 \mathrm{~h}+$ деформация, $p=0.45 \mathrm{GPa}$,

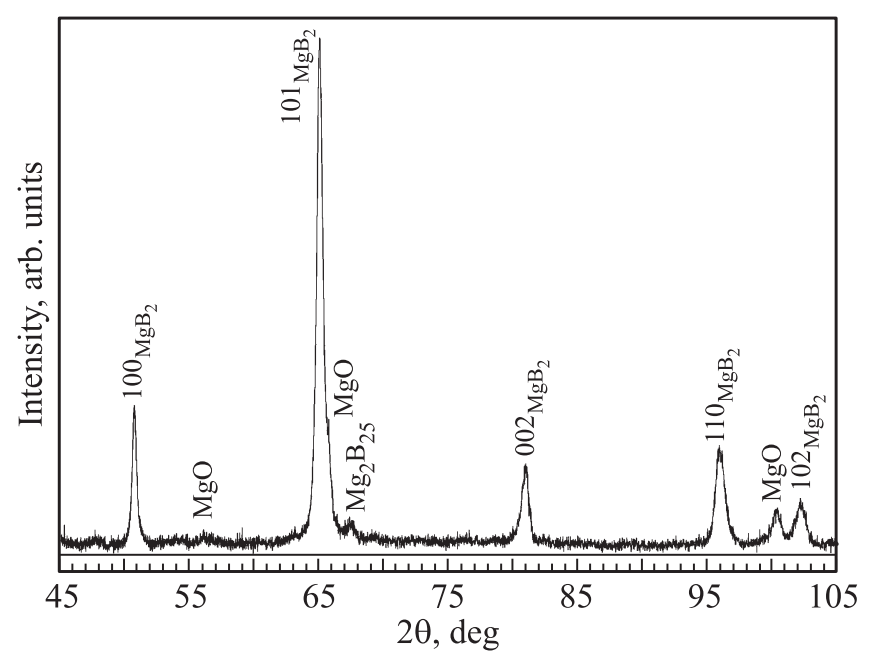

Рис. 7. Участок дифрактограмм образца № 4. Обработка: деформация $P=0.9 \mathrm{GPa}, \alpha=0^{\circ}+$ отжиг $800^{\circ} \mathrm{C}$, $1 \mathrm{~h}+$ деформация $P=0.45 \mathrm{GPa}, \alpha=0^{\circ}+$ отжиг $800^{\circ} \mathrm{C}, 1 \mathrm{~h}$. Излучение $\mathrm{Cr} K_{\alpha}$.

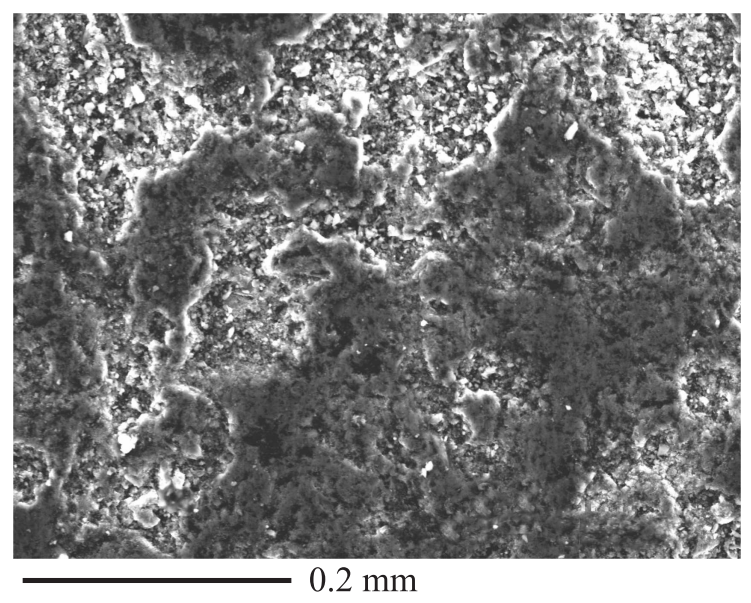

Рис. 8. Сканирующая электронная микроскопия образца № 4. Обработка: деформация $P=0.9 \mathrm{GPa}, \alpha=0^{\circ}+$ отжиг $800^{\circ} \mathrm{C}$, $1 \mathrm{~h}+$ деформация $P=0.45 \mathrm{GPa}, \alpha=0^{\circ}+$ отжиг $800^{\circ} \mathrm{C}, 1 \mathrm{~h}$.

$\alpha=0+$ отжиг $800^{\circ} \mathrm{C}, 1 \mathrm{~h}$. Образец № 4 был подвергнут меньшей, по сравнению с образцом № 3, степени деформации. Деформация состояла из одноосного прессования без поворота наковальни. Фазовый состав образца № 4 в исходном состоянии и после деформации такой же, как образца № 3 (см. рис. 5,a), т. е. в образце присутствует остаточный магний. В результате осуществления при $800^{\circ} \mathrm{C}$ описанного выше жидкостного механизма формирования фазы $\mathrm{MgB}_{2}$ магний практически исчезает (рис. 7). При этом формируется типичная для синтезированных (исходных) образцов структура с большим количеством рыхлых областей (рис. 8). Таким образом, для всех четырех образцов структурная картина после завершения обработок одинакова.

Следует отметить, что во всех исследованных образцах после термомеханических обработок присутству- 
ет небольшое количество $\mathrm{MgO}$. Возможны два пути возникновения этого оксида. Первый путь: во время последеформационного отжига кислород вступает в реакцию с остаточным магнием с образованием $\mathrm{MgO}$. В этом случае частицы получаются крупными и располагаются обычно локально. Второй путь возникновения частиц $\mathrm{MgO}$ заключается в следующем: атомы кислорода вытесняют из решетки $\mathrm{MgB}_{2}$ атомы бора, занимают их позиции; в конечном итоге образуются частицы $\mathrm{MgO}$. Последние должны быть равномерно распределены по всему объему фазы $\mathrm{MgB}_{2}$ [8]. Мы в своей работе [9] методом ПЭМ также наблюдали образование равномерно распределенных мелкодисперсных частиц фазы $\mathrm{MgO}$ в матрице $\mathrm{MgB}_{2}$. В работах многих исследователей утверждается [10-14], что включения $\mathrm{MgO}$ в небольших количествах в матричной фазе $\mathrm{MgB}_{2}$ могут благотворно влиять на сверхпроводящие свойства материала, если, конечно, обеспечена хорошая связь между зернами $\mathrm{MgB}_{2}$ матрицы. Надо полагать, что частицы $\mathrm{MgO}$, которые образуются путем распада соединения $\mathrm{MgB}_{2}$, являются более эффективными центрами пиннинга, чем те, что образуются путем окисления остаточного магния.

Мы привели результаты экспериментов, включающих разную степень деформации и разные температуры отжига (выше температуры плавления магния), для того, чтобы показать, что реакция растворения фазы $\mathrm{MgB}_{2}$ и остаточного бора в остаточном жидком $\mathrm{Mg}$ с последующей кристаллизацией и образованием двух фракций фазы $\mathrm{MgB}_{2}$ (плотной и рыхлой) происходит как во время синтеза из порошков $\mathrm{Mg}$ и $\mathrm{B}$, так и во время термомеханической обработки уже синтезированного образца $\mathrm{MgB}_{2}$. Необходимыми условиями для этой реакции являются наличие хотя бы небольшого количества свободного $\mathrm{Mg}$ и нагрев образца выше температуры плавления магния. Возникающая при этом рыхлая фракция неблагоприятно влияет на критический ток сверхпроводника $\mathrm{MgB}_{2}$. Однако у этих обработок (деформация + отжиг) есть и свои положительные стороны. Во-первых, образцы становятся практически однофазными $\left(\mathrm{MgB}_{2}\right)$, исчезает остаточный $\mathrm{Mg}$. Во-вторых, уменьшается разница в содержании основных элементов $(\mathrm{Mg}, \mathrm{B})$ и кислорода в плотных и рыхлых областях образцы становятся химически более однородными.

Представленные результаты имеют и практическое значение. Опубликованы работы, в которых массивные образцы $\mathrm{MgB}_{2}$ и ex situ композиты на основе $\mathrm{MgB}_{2}$ подвергались деформации с последующим отжигом при высокой температуре. Если при этом в исходном состоянии имеется некоторое количество остаточного магния (на приводимых дифрактограммах синтезированных образцов $\mathrm{MgB}_{2}$ часто наблюдаются линии $\mathrm{Mg}$ ), то происходит описанная выше реакция. В результате возникает структура, характерная для исходного состояния (после синтеза), а именно в образце появляются рыхлые области, что не способствует высоким токам.

\section{4. Заключение}

Методами рентгенографии, сканирующей электронной микроскопии и микроанализа исследован ряд образцов $\mathrm{MgB}_{2}$, которые были подвергнуты деформации под давлением с последующими отжигами при 800 и $950^{\circ} \mathrm{C}$. В исходном состоянии (после синтеза) все эти образцы состоят из двух фракций - плотных и рыхлых областей фазы $\mathrm{MgB}_{2}$. После деформации под давлением в наковальнях Бриджмена (давление до $1.4 \mathrm{GPa}$, угол поворота до $45^{\circ} \mathrm{C}$ ) образцы уплотняются, практически исчезают рыхлые области, микротвердость поднимается в среднем до $\sim 27 \mathrm{GPa}$. После указанных выше отжигов структура всех исследованных образцов возвращается к исходному состоянию. Это является результатом действия жидкостного механизма образования фазы $\mathrm{MgB}_{2}$ : кристаллы фазы $\mathrm{MgB}_{2}$ вместе с остаточным бором растворяются в остаточном жидком магнии с последующей кристаллизацией из расплава $\mathrm{Mg}: \mathrm{B}=1: 2$ и образованием плотных и „загрязненных“ рыхлых областей. При этом плотные области фазы $\mathrm{MgB}_{2}$ в первую очередь образуются и растут с большей скоростью в участках порошкового бора, хорошо пропитанных жидким магнием, по причине большой площади контакта $\mathrm{Mg}$ и В. Отметим, что указанные обработки (деформация + высокотемпературный отжиг) часто применяют по отношению к массивным образцам $\mathrm{MgB}_{2}$ и ex situ композитам с $\mathrm{MgB}_{2}$. В связи с этим нужно иметь в виду, что во время высокотемпературного отжига (выше температуры плавления магния) при наличии в образце даже небольшого количества остаточного магния будут возникать рыхлые области, которые не благоприятствуют повышению критического тока. Есть у обработки (деформация + отжиг) и свои положительные стороны: количество сопутствующих фаз резко уменьшается, распределение элементов $\mathrm{Mg}, \mathrm{B}, \mathrm{O}$ по образцу становится более однородным.

\section{Список литературы}

[1] Е.И. Кузнецова, С.В. Сударева, Т.П. Криницина, Ю.В. Блинова, Е.П. Романов, Ю.Н. Акшенцев, М.В. Дегтярев, М.А. Тихоновский, И.Ф. Кисляк. ФММ 115, 186 (2014).

[2] Е.И. Кузнецова, Ю.Н. Акшенцев, В.О. Есин, С.В. Сударева, Ю.В. Блинова, М.В. Дегтярев, В.И. Новоженов, Е.П. Романов. ФТТ 57, 873 (2015).

[3] S.C. Yan, G. Yan, C.F. Liu, Y.F. Lu, L. Zhou. J. All. Comp. 437, 298 (2007).

[4] J.M. Hur, K. Togano, A. Matsumoto, H. Kumakura, H. Wada. Supercond. Sci. Technol. 21, 032001 (2008).

[5] A.G. Bhagurkar, A. Yamamoto, N. Hari Babu, J.H. Durrell, A.R. Dennis, D.A. Cardwell. Supercond. Sci. Technol. 28, 015012 (2015).

[6] Y.C. Liu, Q.Z. Shi, Q. Zhao, Z.Q. Ma. J. Mater. Sci.: Mater. Electron 18, 855 (2007).

[7] Z.Q. Ma, Y.C. Liu. Int. Mater. Rev. 56, 267 (2011).

[8] X.Z. Liao, A. Serquis, Y.T. Zhu, J.Y. Huang, L. Civale, D.E. Peterson, F.M. Mueller, H.F. Xu. J. Appl. Phys. 93, 6208 (2003). 
[9] Е.И. Кузнецова, Т.П. Криницина, Ю.В. Блинова, М.В. Дегтярев, С.В. Сударева. ФММ 118, 364 (2017).

[10] T.A. Prikhna, M. Eisterer, H.W. Weber, W. Gawalek, V.V. Kovylaev, M.V. Karpets, T.V. Bayuk, V.E. Moshchil. Supercond. Sci. Technol. 27, 044013 (2014).

[11] Y. Zhu, L. Wu, V. Volkov, Q. Li, G. Gu, A.R. Moodenbaugh, M. Malac, M. Suenaga, J. Tranquada. Physica C 356, 239 (2001).

[12] P. Kovac, I. Husek, T. Melisek, J.C. Grivel, W. Pachla, V. Strbik, R. Diduszko, J. Homeyer, N.H. Andersen. Supercond. Sci. Technol. 17, L41 (2004).

[13] M. Vignolo, G. Romano, A. Malagol, V. Braccini, M. Tropeano, E. Bellinger, C. Fanciulli, C. Bernini, V. Honkimaki, M. Putti, C. Ferdeghini. IEEE Trans. Appl. Supercond. 19, 2718 (2009).

[14] C.B. Eom, M.K. Lee, J.H. Choi, L.J. Belenky, X. Song, L.D. Cooley, M.T. Naus, S. Patnaik, J. Jiang, M. Rikel, A. Polyanskii, A. Gurevich, X.Y. Cai, S.D. Bu, S.E. Babcock, E.E. Hellstrom, D.C. Larbalestier, N. Rogado, K.A. Regan, M.A. Hayward, T. He, J.S. Slusky, K. Inumaru, M.K. Haas, R.J. Cava. Nature 411, 588 (2001). 